\title{
An Investigation of the Knowledge, Attitude and Practice of Family Caregivers of Patients with Alzheimer's Disease
}

\author{
Liu Guilin ${ }^{1}$, Lin Qingran ${ }^{2, ~}$, Huang Ruiying ${ }^{3}$, Zhai Cuiqiu $^{3}$, Li Yunjia ${ }^{1}$ \\ ${ }^{1}$ Department of Nursing, Jinan University, Guangzhou, China \\ ${ }^{2}$ Department of Nursing, The First Affiliated Hospital of Jinan University, Guangzhou, China \\ ${ }^{3}$ Department of Long-Term Care Center, The First Affiliated Hospital of Jinan University, Guangzhou, China
}

Email address:

qingranlin@sina.com (Lin Qingran)

${ }^{*}$ Corresponding author

\section{To cite this article:}

Liu Guilin, Lin Qingran, Huang Ruiying, Zhai Cuiqiu, Li Yunjia. An Investigation of the Knowledge, Attitude and Practice of Family Caregivers of Patients with Alzheimer's Disease. International Journal of Psychological and Brain Sciences. Vol. 4, No. 1, 2019 , pp. 1-6. doi: 10.11648/j.ijpbs.20190401.11

Received: March 21, 2019; Accepted: April 25, 2019; Published: May 23, 2019

\begin{abstract}
Objective To investigate the current status of the knowledge, attitude and practice (KAP) of primary home caregivers of patients with Alzheimer's disease (AD). To propose targeted intervention measures to improve home caregivers' ability of caring, by analyzing influencing factors. Methods 76 family caregivers of patients diagnosed as AD in a third-class hospital in Guangzhou were selected for this survey of convenient sampling. These patients were followed up at home after discharge from the hospital, and their main family caregivers were investigated by knowledge, attitude, practice questionnaire. Results The total scores of knowledge, attitude and practice of the home caregivers of AD patients respectively were (53.16 \pm 8.78$),(33.53 \pm 4.69),(56.34 \pm 13.39)$. There were statistically significant differences between the self-care ability of patients, the occurrence of $\mathrm{AD}$ symptoms and the knowledge score of caregivers $(\mathrm{P}<0.05)$. The age of the caregiver was negatively correlated with attitude. The younger caregiver obtained the higher attitude score. And more knowledge about the patient's condition resulted in higher practice score and care ability. Conclusions The scores of home caregivers of patients with $\mathrm{AD}$ remain low in knowledge, attitude and practice, so it is necessary to strengthen the health education and care guidance for these caregivers. In this way, the caregivers can obtain more social support to improve their ability to care for patients.
\end{abstract}

Keywords: Alzheimer's Disease, Family Caregiver, Home Care, Knowledge, Attitude and Practice

\section{Introduction}

Alzheimer's disease is a neurodegenerative disorder with insidious onset and progressive declines. It is characteristic of such symptoms of general dementia as memory impairment, aphasia, apraxia, agnosia, impaired visuospatial skills, executive dysfunction, and personality and behavior changes. There are 10 million people suffering from Alzheimer's disease now in China. According to epidemiological data, the number is expected to surpass 131.5 million by 2050 [1]. Patients with AD need long-term home caring which is not only costly but also renders heavy physical, financial and psychological burdens on the caregivers' shoulders [2]. Their knowledge, attitude and practice have direct influence on the quality of home caring for the AD patients. High-quality nursing care can halt disease progression and reduce complications [3]. The KAP theoretical model divides the process of behavior change into three continuous steps namely knowledge acquisition, attitude change and behavioral formation. It is widely adopted in the field of health education and promotion [4]. Currently there is a lack of domestic and overseas study on the general status of knowledge, attitude and practice of family caregivers of patients with $\mathrm{AD}$. Therefore, the current article attempts to conduct an investigation into the status of the knowledge, attitude and practice of the family caregivers of $\mathrm{AD}$ patients. With the investigation, we expect to provide guidance for these home caregivers to acquire disease knowledge, change attitude and improve their ability of caring. Then a home intervention program for patients with $\mathrm{AD}$ will be explored and set up. 


\section{Participants and Methods}

\subsection{Participants}

We included 76 family caregivers of patients diagnosed with AD in a third-grade class-A hospital in Guangzhou from February to August 2018. The included participants should meet the following criteria: the patients receiving care from them should meet the diagnostic criteria of Alzheimer's disease in Diagnostic and Statistical Manual of Mental Disorders (5 $5^{\text {th }}$ Edition) released by American Psychiatric Association and in International Classification of Diseases $\left(10^{\text {th }}\right.$ Edition); the caregivers were at the age of $\geq 18$ and provided physical and psychological support for patients for over 3 three months; the chosen caregiver in a family was the one who provided care for the longest time among other family caregivers if any; the caregivers had normal comprehension and communication ability and were voluntary to participate in the investigation, signing their informed consents. Caregivers whose patients were staying in the nursing institution for the aged or hospitalized at recovery stage were excluded.

\subsection{Methods}

\subsubsection{Investigation Methods}

Convenience sampling was adopted to select family caregivers of patients diagnosed with $\mathrm{AD}$ in a third-grade class-A hospital in Guangzhou. After receiving consents from the patients' family members and their family caregivers, a follow-up on long-term care was given to the family caregivers at home. The survey team was composed of two graduate students majoring in continuing nursing care and one clinical nurse specialist. After receiving training of how to use questionnaires and conduct home follow-up, the team paid a follow-up visit to the caregivers of $\mathrm{AD}$ patients, and distributed and collected the questionnaires on knowledge, attitude and practice of the caregivers on the spot. Seventy-six questionnaires were distributed and 73 were collected with a recovery rate of $96.05 \%$.

\subsubsection{Investigation Tools}

\section{(i) General Information Questionnaire}

The information included patients' information (name, gender, age, disease severity, self-care ability, duration of AD symptoms, when the definite diagnosis was made), and caregivers' information (gender, age, native place, nationality, religion, profession, income, level of education, marital status, physical condition, how long they have provided care for the AD patients and their knowledge of the patient's condition).

(ii) Questionnaire on Caregivers' Knowledge, Attitude and Practice

$i$ The Knowledge section mainly referred to an Alzheimer's Disease Knowledge Scale (ADKS) [5] which was used to evaluate caregivers' knowledge of nursing care for dementia. The scale contains 30 items focusing on 7 dimensions, with a test-retest reliability of 0.81 and internal consistency reliability, Cronbach's $\alpha=0.71$. A standard score is calculated by summing the correct scores for each item (1 point for a correct answer and 0 for a wrong one), dividing it by 30 and then multiplying the figure by 100 (standard score $=$ total score $/ 30 * 100)$. The standard score is graded as three classes: A, B, C, with $\mathrm{A}>80, \mathrm{~B}=60 \sim 80$, and $\mathrm{C}<60$.

ii Attitude section was Positive Aspects of Caregiving (PAC) [6] which was used to assess the positive feelings of primary caregivers of senile dementia patients. It includes 9 items focusing on 2 dimensions: self-affirmation and outlook on life. The five-point Likert-type scale, with a total score of 45 , requires participants to respond to each statement with one of the five choices ranging from "strongly disagree" (1 point) to "totally agree" (5 points). A higher score indicates more positive feeling. The Cronbach's $\alpha$ of the scale is 0.89 .

iii In the Practice section was a Family Caregiving Task Inventory (FCTI) [7] which is a 25 -item five-point Likert-type scale focusing on 5 dimension: adaptation to the role of caregiver, response to emergency and providing support, handling personal emotions, assessing family and community resources, adjusting life to meet the need of caring. The participants respond to each item with one of the five levels of difficulty description from "not difficult" to "very difficult" under each statement. The total score is 125 and a higher score indicates more difficulties in caring for the patients and lower ability of caring. The inventory with Cronbach's $\alpha$ of 0.87 has been used in measuring the caring ability of caregivers of patients with stroke, cancer [8] and other chronic diseases, or undergoing enterostomy [9].

\subsection{Statistical Methods}

Two members were responsible for entering the data using SPSS 19.0 Software for statistical analysis. The general data were described with frequency and constituent ratio. Scores in Knowledge, Attitude and Practice were presented in $\overline{\mathrm{x}} \pm \mathrm{S}$. T-test and variance analysis were employed for the analysis of the scores of different people, Spearman correlation analysis for ordinal data, linear correlation regression analysis for age and other variables, and canonical correlation analysis for the overall correlation between the indicators of three scales. $\mathrm{P}$ $<0.05$ indicates statistical significance in difference.

\section{Results}

\subsection{General Data of Patients with AD and Their Caregivers}

According to the investigation, the average age of patients with $\mathrm{AD}$ was $81.73 \pm 7.27$, and their symptoms had lasted $5.67 \pm 5.51$ years on average. According to the advance of the disease and severity of cognitive impairment, $53.4 \%$ of patients suffered severe impairment in self-care ability. Their family caregivers were at an average age of $57.05 \pm 12.20$, among whom females took up $84.9 \%$ and employed 
caregivers took up $64.4 \%$. Caregivers who were inclined to wake up at night accounted for $52.1 \%$, and those who had much knowledge of the patients took up 50.7\%. Details are described in Table 1.

Table 1. General Information of the Patients and Caregivers.

\begin{tabular}{|c|c|c|c|c|}
\hline Participants & Items & Categories & Number & constituent ratio (\%) \\
\hline \multirow[t]{8}{*}{ Patients } & \multirow[t]{2}{*}{ Gender } & Male & 29 & 39.7 \\
\hline & & Female & 44 & 60.3 \\
\hline & \multirow[t]{3}{*}{ Severity of disease } & Mild (MMSE: 21-30 score) & 14 & 19.2 \\
\hline & & Moderate (MMSE: 11-20) & 20 & 27.4 \\
\hline & & Severe (MMSE: $\leq 10)$ & 39 & 53.4 \\
\hline & \multirow[t]{3}{*}{ Self-care ability } & Totally independent (BADL: 61-100 score) & 11 & 15.1 \\
\hline & & Needing help most of the time (BADL: 21-40) & 8 & 11.0 \\
\hline & & Totally dependent (BADL: $\leq 20)$ & 39 & 53.4 \\
\hline \multirow[t]{36}{*}{ Caregivers } & \multirow[t]{2}{*}{ Gender } & Male & 11 & 15.1 \\
\hline & & Female & 62 & 84.9 \\
\hline & \multirow[t]{2}{*}{ Nationality } & Han Nationality & 70 & 95.9 \\
\hline & & Minority & 3 & 4.1 \\
\hline & Religion & no & 69 & 94.5 \\
\hline & \multirow[t]{4}{*}{ State of occupation } & work & 7 & 9.6 \\
\hline & & retirement & 14 & 19.2 \\
\hline & & freelancer & 5 & 6.8 \\
\hline & & none & 47 & 64.4 \\
\hline & \multirow[t]{6}{*}{ Income } & $>10000$ (RMB) & 2 & 2.7 \\
\hline & & $5000 \sim$ & 20 & 28.5 \\
\hline & & $3000 \sim$ & 38 & 52.1 \\
\hline & & $1000 \sim$ & 6 & 8.2 \\
\hline & & $<1000$ & 2 & 2.7 \\
\hline & & none & 5 & 6.8 \\
\hline & \multirow[t]{4}{*}{ Level of education } & illiteracy & 5 & 6.8 \\
\hline & & Primary school degree & 14 & 19.2 \\
\hline & & Junior high school degree & 31 & 42.5 \\
\hline & & Bachelor or above & 6 & 8.2 \\
\hline & \multirow[t]{4}{*}{ Marital status } & Single & 1 & 1.4 \\
\hline & & Married & 70 & 95.8 \\
\hline & & Divorced & 1 & 1.4 \\
\hline & & Widowed & 1 & 1.4 \\
\hline & \multirow[t]{4}{*}{ Family status } & Living alone & 1 & 1.4 \\
\hline & & Living with spouse & 27 & 37.0 \\
\hline & & Living with children & 6 & 8.2 \\
\hline & & Living with others & 39 & 53.4 \\
\hline & \multirow[t]{6}{*}{ Duration of caregiving } & $>10$ years & 18 & 24.7 \\
\hline & & $6 \sim 10$ years & 12 & 16.4 \\
\hline & & $4 \sim 5$ years & 3 & 4.1 \\
\hline & & $1 \sim 3$ years & 20 & 27.4 \\
\hline & & $7 \sim 12$ months & 12 & 16.4 \\
\hline & & $4 \sim 6$ months & 8 & 11.0 \\
\hline & \multirow[t]{3}{*}{$\begin{array}{l}\text { Knowledge of the condition of } \\
\text { patients }\end{array}$} & All & 19 & 26.0 \\
\hline & & Most & 37 & 50.7 \\
\hline & & A little & 17 & 23.3 \\
\hline
\end{tabular}

\subsection{General Condition of Caregivers' Knowledge, Attitude} and Practice

The caregivers' scores on knowledge, attitude and practice were $(58.54 \pm 7.41),(33.53 \pm 4.69),(56.34 \pm 13.39)$ respectively.
Score in knowledge was associated with patients' self-care ability ( $\mathrm{rs}=-0.26, \mathrm{P}=0.03$ ) and duration of the symptoms $(\mathrm{t}=-2.03, \mathrm{P}=0.05)$. Attitude was related to caregivers' age $(\mathrm{t}=-2.16, \mathrm{P}=0.04)$ and knowledge of the disease was correlated with caregivers' ability of caregiving ( $\mathrm{rs}=0.38, \mathrm{P}=0.01)$. 
Details are shown in Table 2. The average score in the ability statistic significance $(\mathrm{F}=40.65, \mathrm{P}=0.00)$ as shown in Table 3 . of caregiving of the five items were different, and there was a

Table 2. Score Analysis of Knowledge, Attitude and Practice Scale for Different Caregivers.

\begin{tabular}{|c|c|c|c|c|c|}
\hline participants & Items & Categories & Score in knowledge & Score in attitude & Score in practice \\
\hline \multirow{9}{*}{ Patients } & Total score & & $58.54 \pm 7.41$ & $33.54 \pm 4.69$ & $56.34 \pm 13.39$ \\
\hline & \multirow[t]{6}{*}{ Self-care ability } & Totally independent & $63.63 \pm 4.07$ & $32.55 \pm 5.24$ & $55.55 \pm 14.77$ \\
\hline & & Needing help occasionally & $57.78 \pm 8.42$ & $32.60 \pm 5.80$ & $54.07 \pm 17.15$ \\
\hline & & Needing help most of the time & $60.83 \pm 7.07$ & $34.75 \pm 5.12$ & $51.38 \pm 14.84$ \\
\hline & & Totally dependent & $56.92 \pm 7.07$ & $33.92 \pm 4.62$ & $58.46 \pm 11.02$ \\
\hline & & $r_{s}$ & -0.29 & 0.28 & 0.23 \\
\hline & & $\mathrm{P}$ & 0.01 & 0.13 & 0.05 \\
\hline & \multirow[t]{2}{*}{ Duration of symptoms } & $\mathrm{r}$ & -0.24 & 0.09 & -0.02 \\
\hline & & $\mathrm{P}$ & 0.04 & 0.46 & 0.85 \\
\hline \multirow[t]{12}{*}{ Caregivers } & \multirow[t]{7}{*}{ Age } & $30 \sim$ & $60.56 \pm 2.51$ & $35.17 \pm 5.23$ & $52.33 \pm 9.87$ \\
\hline & & $40 \sim$ & $59.44 \pm 8.14$ & $34.92 \pm 2.11$ & $57.67 \pm 9.62$ \\
\hline & & $50 \sim$ & $57.92 \pm 8.04$ & $33.94 \pm 4.82$ & $56.31 \pm 10.72$ \\
\hline & & $60 \sim$ & $57.22 \pm 9.76$ & $31.50 \pm 5.79$ & $62.00 \pm 16.97$ \\
\hline & & $70 \sim$ & $58.82 \pm 6.34$ & $31.94 \pm 4.97$ & $54.88 \pm 19.45$ \\
\hline & & $r_{s}$ & -0.17 & -0.21 & -0.06 \\
\hline & & $P$ & 0.16 & 0.04 & 0.60 \\
\hline & \multirow[t]{5}{*}{ Knowledge of patients' disease } & all & $57.89 \pm 7.04$ & $33.05 \pm 5.46$ & $49.14 \pm 10.04$ \\
\hline & & Most & $57.84 \pm 7.71$ & $33.86 \pm 4.52$ & $60.50 \pm 18.06$ \\
\hline & & A little bit & $60.78 \pm 7.12$ & $33.35 \pm 4.34$ & $56.79 \pm 10.67$ \\
\hline & & $r_{s}$ & 0.14 & -0.07 & 0.38 \\
\hline & & $\mathrm{P}$ & 0.25 & 0.54 & 0.00 \\
\hline
\end{tabular}

Table 3. Single Factor Analysis of Each Item in the Caregiver Competency Scale.

\begin{tabular}{llllll}
\hline Dimensions & $\begin{array}{l}\text { Adaptation to } \\
\text { the role of } \\
\text { caregiver }\end{array}$ & $\begin{array}{l}\text { Providing care } \\
\text { according to the need } \\
\text { of the patients }\end{array}$ & $\begin{array}{l}\text { Management of } \\
\text { personal } \\
\text { emotional needs }\end{array}$ & $\begin{array}{l}\text { Bbility to assess family and to } \\
\text { seek social support resources }\end{array}$ & $\begin{array}{l}\text { Balancing } \\
\text { caregiving and } \\
\text { personal needs }\end{array}$ \\
\hline Mean value & $8.32 \pm 2.00$ & $12.67 \pm 3.71$ & $9.45 \pm 3.29$ & $14.63 \pm 3.59$ & $11.27 \pm 3.89$ \\
$F$ & 0.47 & 33.40 & 9.69 & 36.20 & $11.27 \pm 4.04$ \\
$P$ & 0.62 & 0.00 & 0.00 & 0.00 & 40.65 \\
0.00 & 0.00 \\
\hline
\end{tabular}

\subsection{Correlation Analysis of Knowledge, Attitude and Practice (Scales)}

The canonical correlation analysis was performed between the set of $\mathrm{X}$ variables composed of 7 dimensions of family caregiver's knowledge and the set of Y variables composed of 2 dimensions of attitude. The first canonical correlation coefficient was $\mathrm{r} 1=0.447$, and the second canonical correlation coefficient was $r 2=0.209$. The likelihood ratio test showed no statistical significance. The contribution rate of the first canonical variable was $84.49 \%$ and that of the second canonical variable was $15.51 \%$. According to $\mathrm{U} 1=$ 0.258Y1-0.111Y2-0.428Y3+0.462Y4-0.771Y5+0.190Y6-0.1 $24 \mathrm{Y} 7, \mathrm{~V} 1=0.404 \mathrm{X} 1-1.257 \mathrm{X} 2$, attitude was mainly affected by level of knowledge of caregiving, life and course of disease. Lower score in knowledge meant more negative outlook on life. There was no correlation between knowledge and attitude. The canonical correlation analysis was performed between the set of $\mathrm{X}$ variables composed of 7 dimensions of family caregivers' knowledge and the set of A variables composed of 5 dimensions of practice. The five canonical correlation coefficients were not statistically significant. According to U2= 0.157Y1-0.001Y2-0.416Y3-0.101Y4-0.709Y5-0.331Y6+0.229 $\mathrm{Y} 7, \quad \mathrm{~V} 2=\quad 0.171 \mathrm{~A} 1-0.162 \mathrm{~A} 2+0.820 \mathrm{~A} 3+0.227 \mathrm{~A} 4+0.095 \mathrm{~A} 5$, practice was mainly affected by knowledge of caregiving and course of disease, and knowledge was affected by caregivers' ability to adjust life to meet the needs of the patients. There was no significant correlation between knowledge and ability. The canonical correlation analysis was performed between the $\mathrm{Y}$ variable set consisting of two dimensions of family caregivers' attitude and the A variable set consisting of five dimensions of practice. The first canonical correlation coefficient was $r 1=0.603$ and the second canonical correlation coefficient was $\mathrm{r} 2=0.298$. The likelihood ratio test demonstrated that there was statistical significance in the first canonical correlation coefficient $(\mathrm{P}=0.000)$. The contribution rate of the first canonical variable was $85.37 \%$. According to $\mathrm{U} 3=0.049 \mathrm{X} 1+0.964 \mathrm{X} 2$, V3 $=$ $0.086 \mathrm{~A} 1+0.690 \mathrm{~A} 2-1.567 \mathrm{~A} 3-0.199 \mathrm{~A} 4+0.370 \mathrm{~A} 5$, the practice was mainly affected by caregivers' outlook on life and attitude was affected by ability to deal with emergency, to provide assistance and to cope with personal emotions. Attitude was highly correlated to practice (correlation coefficient $=0.603, \mathrm{P}=$ 0.000 ). The correlation between caregivers' attitude and practice was mainly because of the correlation between outlooks on life and ability to deal with emergency, to provide assistance and to cope with personal emotions.

\section{Discussion}

\subsection{Knowledge, Attitude and Practice of Family Caregivers of Patients with Alzheimer's Disease}

\subsubsection{Lack of Knowledge}

The average score in knowledge of family caregivers of 
patients with $\mathrm{AD}$ is $58.54 \pm 7.41$ remaining in a lower level. The family caregivers lack knowledge of care in disease. Most of the family caregivers are home carers and are of lower level of education, of whom $68.5 \%$ have junior high school degree or below. There is a decrease in the ability to acquire knowledge of caregivers over the age of 60, accounting for $33.19 \%$, which is consistent with other studies [10]. Family caregivers have limited sources of knowledge, some of which come from their own and others' experiences [11], lacking professional, standard and targeted training. The family caregivers have low perception of Alzheimer's disease, believing that $\mathrm{AD}$ is a normal physiological degradation with age, rather than a disease. Their negative attitude affects their knowledge of the disease. Treatments are focused on complications of $\mathrm{AD}$ and prevention and diagnosis of are ignored. As a result, when the patient is diagnosed with $\mathrm{AD}$, the optimal intervention time has been missed failing to delay the disease progression of the patient [12].

\subsubsection{Correlation Between Caregiver's Positive Attitude and Age and Level of Income}

The caregivers' average score in attitude is $33.54 \pm 4.69$. The standardized score on a percentage scale is 74.53 at a moderate level. Although care in Alzheimer's disease has gradually attracted researchers' attention and related articles have increased, the focus of the existent studies are on the nursing care, places of getting care, improvement of symptoms after care, etc. There is a lack of focus on attitude of caregivers.

The current study finds that caregivers get lowest score in receiving gratitude and respect, which is associated with low social acceptance of caregivers and psychological damage to caregivers caused by unstable emotional state of patients with AD. Older caregivers tend to have more negative feelings. Some of them are the spouses of the patients. So they take it for granted to take care of each other and do not recognize their own value. As a result, they are not positive enough in self-affirmation and outlook on life.

Income level has impact on caregivers' positivity. The value of caregivers contributes to their positive attitude, responsibility and caregiving. Currently, according to specific treatment standard, the long-term nursing care insurance system implemented in Guangzhou is favorable to home care and home caregivers of the insured can receive some financial support. But in the pilot implementation of the long-term nursing care insurance [13], some patients with AD are not eligible for application. For some eligible patients, their caregivers do not know how to apply for the subsidy. Therefore, improvement is needed to be done in publicity of related policies and financial support, management of patients with $\mathrm{AD}$ and establishment of home care system for patients with $\mathrm{AD}$ by government and hospitals.

\subsubsection{Insufficient Ability of Caring of Caregivers}

The order of family caregivers' caregiving ability in 5 dimensions is: adaptation to the role of caregiver $>$ management of personal emotional needs $>$ providing care according to the need of the patients $>$ balancing caregiving and personal needs $>$ ability to assess family and to seek social support resources. At present, the management of $\mathrm{AD}$ is not standardized and there is a lack of cooperation between different departments. The social support system such as community health and medical services, social organizations support, social workers and volunteers needs to be further improved, which results in the shortage of social support resources for patients and their caregivers. The caregivers can only improve care ability on their own through adapting to the caregiving environment, controlling their emotions and taking care of the patients according to patients' needs. However, patients with dementia and disability needs more care, and caregivers cannot avoid the physical and time consumption in nursing patients, so they have no time to adjust their lives. What's more the caregivers lack solution to dealing with behavioral and psychological symptoms of some patients. Hence, personal and general factors contribute to low overall care ability of caregivers.

\subsection{Correlation Between Knowledge, Attitude and Practice}

Knowledge is the foundation, positive attitude is the motivation, and good practice is the goal but there is no positive connection between the three. The current study suggests that more positive attitude leads to better care ability, which is consistent with other studies. Those who hold more positive attitude towards life find it easier to adapt to the role of a caregiver because they are more inclined to seek solutions when confronted with difficulties, which contributes to increase in care ability. The more a caregiver knows about the disease, the higher his/her care ability is. Some scholars [14] have developed training program for home care and provided one-on-one training and guidance on standard knowledge and skills of caregiving for caregivers in Shanghai. These scholars' studies have increased caregivers' knowledge of disease and thus their care ability, and met the needs of home care, which is consistent with the present study. Their training methods are worth learning. In the current study there is no significant correlation between knowledge and attitude. Although a caregiver knows about the disease and patients well, he/she may still have negative attitude because the special status of $\mathrm{AD}$ patients and great difficulty in caregiving may render a caregiver feel disappointed and doubt or even deny the role of correct nursing care in delaying the progression of disease. This suggests that we need to not only develop appropriate training program to increase caregivers' knowledge of caring for patients with $\mathrm{AD}$ but also help them develop positive attitude to strengthen their awareness of the necessary role of correct home care so as to enhance the practice of caregiving and care ability. We also suggest combining resources of society, organizations and communities to form a league with a multi-disciplinary professional $\mathrm{AD}$ management team of tertiary hospitals as the core. Besides, the role of each team member should be fully developed and management of patients with $\mathrm{AD}$ should be strengthened through various activities. Promotion of knowledge of caregiving and insurance of the disease should be enhanced. Public awareness of the disease, its caregiving, prevention and diagnosis should 
be raised. In addition, home caregivers should be given standard training including specific communication skills, knowledge and skills of safe caregiving, strategies for psychological symptoms and behaviors, application for long-term nursing care insurance, etc. But improvement in training is necessary to enhance caregivers' interest. Psychological counselling and guidance, and respite service [15] can be provided for the caregivers to help them develop positive attitude and enhance ability to care for patients. Hence, both caregivers' knowledge, attitude and practice of caring and patients' life quality can be improved.

\section{Conclusions}

The knowledge, attitude and practice of caregivers of patients with $\mathrm{AD}$ remain at a low level. Most caregivers still lack related knowledge, positive attitude and qualified care ability. Standardized management of caregivers of patients with $\mathrm{AD}$ and professional health education guidance and training for them have not yet been established. There is a lack of public concern on the caregivers and financial support, which affects home care for patients with AD. The limitation of this study lies in that the investigation is limited to only one public third-grade class-A hospital because of constraints on time, manpower and money. As a result the sample size is too small. Thus samples collected from multiple institutions can be adopted in the future study to further explore factors influencing knowledge, attitude and practice of caregivers of patients with $\mathrm{AD}$ so as to provide scientific basis for a more effective home care program.

\section{Acknowledgements}

This work was financially supported by the Guangdong Medical Science and Technology Research Fund (NO. A2019372).

\section{References}

[1] Chan, K. Y., Wang, W., Wu, J. J., Liu, L., Theodoratou, E., \& Car, J., et al. (2013). Epidemiology of alzheimer's disease and other forms of dementia in china, 1990-2010: a systematic review and analysis. Lancet, 381 (9882), 2016-2023.

[2] Junfang, X., Jian, W., Anders, W., Laura, F., \& Chengxuan, Q.. (2017). The economic burden of dementia in china, 1990-2030: implications for health policy. Bulletin of the World Health Organization, 95 (1), 18-26.

[3] Grabher, B. J.. (2018). Effects of Alzheimer Disease on patients and their family $[\mathrm{J}]$. Journal of nuclear medicine technology. 2018, 46 (4): 335-34.
[4] Abdulcadir J, Say L, Pallitto C. What do we know about assessing healthcare students and professionals' knowledge, attitude and practice regarding female genital mutilation? A systematic review [J]. Reproductive Health, 2017, 14 (1): 64.

[5] Annear, M. J., Eccleston, C. E., Mcinerney, F. J., Elliott, K. E. J., Toye, C. M., \& Tranter, B. K., et al. (2016). A new standard in dementia knowledge measurement: comparative validation of the dementia knowledge assessment scale and the alzheimer|"s disease knowledge scale. Journal of the American Geriatrics Society, 64 (6), 1329-1334.

[6] Abdollahpour, I., Nedjat, S., Noroozian, M., Salimi, Y., \& Majdzadeh, R.. (2017). Positive aspects of caregiving questionnaire. Journal of Geriatric Psychiatry and Neurology, 30 (2), 77-83.

[7] Cohen, C. C., Auslander, G., Dror, Y. F., \& Breuer, G. S. (2016) Functional and existential tasks of family caregiving for end-of-life, hospitalized older adults. Journal of Gerontological Nursing, 42 (7), 55-64.

[8] Bond, S. M., Schumacher, K., Sherrod, A., Dietrich, M. S., Wells, N., \& Lindau, R. H., et al. (2016). Development of the head and neck cancer caregiving task inventory. European Journal of Oncology Nursing, 24, 29-38.

[9] Palma, E., Simonetti, V., Franchelli, P., Pavone, D., \& Cicolini, G. (2012). An observational study of family caregivers' quality of life caring for patients with a stoma. Gastroenterology Nursing, 35 (2), 99-104.

[10] Valente, L. E., Truzzi, A., Souza, W. F., Alves, G. S., Alves, C. E., \& Sudo, F. K., et al. (2011). Health self-perception by dementia family caregivers: sociodemographic and clinical factors. Arquivos de Neuro-Psiquiatria, 69 (5), 739-44.

[11] McNair, \& Tracy. (2015). Early intervention for caregivers of patients with alzheimer's disease. Home Healthc Now, 33 (8), 425-430.

[12] Jutten, R. J., Harrison, J., Lee, P. M. K., Opmeer, E. M., Schoonenboom, N., \& De, F. J., et al. (2018). A novel cognitive-functional composite measure to detect changes in early alzheimer's disease: test-retest reliability and feasibility. Alzheimers \& Dementia, 10, 153-160.

[13] Yan-Ling, Z., Qing, Z., Dan-Ping, X., Pin-Hong, B., \& Yang-Dong, F.. (2017). The choice of long-term nursing insurance system in guangzhou city under the theory of "welfare triangle". Modern Hospital Management, 15 (06): $52-56$.

[14] Wang, J., Xiao, L. D., Guo - Ping He, \& Bellis, A. D.. (2014). Family caregiver challenges in dementia care in a country with undeveloped dementia services. Journal of Advanced Nursing, $70(6), 12$.

[15] Vandepitte, S., Van, D. N. N., Putman, K., Verhaeghe, S., Verdonck, C., \& Annemans, L.. (2016). Effectiveness of respite care in supporting informal caregivers of persons with dementia: a systematic review. Int J Geriatr Psychiatry, 31 (12), 1277-1288. 